\title{
Psychometrics Of Hotel Service Quality: Comparative Factor Structures Of Alternative Market Segments
}

Mark I. Alpert (E-mail: alpertm@mail.utexas.edu), University of Texas at Austin Rajagopal Raghunathan (E-mail: raj.raghunathan@bus.utexas.edu), University of Texas at Austin

\begin{abstract}
When different market segments are encountered, can the same instrument be used to understand and predict the determinants of customer perceptions of service quality, satisfaction and retention? This paper analyzes a national sample of over 18,000 U.S. customer surveys regarding hotel experiences in a range of properties from budget to near-luxury accommodations. Its purpose is to examine the dimensionality of customer satisfaction for business vs. pleasure travelers, and male vs. female guests, in order to determine the appropriateness of conceptualizing and measuring service quality with the same instrument for these potentially divergent segments. Our findings provide good evidence of factor stability across these segments, using the multi-item scales that are employed by one of the largest privately held hotel chains in the United States. Within the common factor structure, modest but intuitively reasonable differences in the importance of service attributes in determining customer loyalty for different segments do emerge.
\end{abstract}

\section{Introduction}

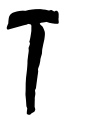

here has been a long-standing interest in the identification of those key features that determine customer patronage and loyalty. These features called "determinant attributes" by Myers and Alpert $(1968,1997)$ are those that are not only important to customers, but also, because they are believed to differ among choice alternatives, thereby are influential in determining what products or services are purchased and repurchased. A large number of methods of identifying determinant attributes have been the focus of research, using methodologies ranging from qualitative "motivation research" to covariate methods (Myers and Alpert, 1968, 1997), including versions of multiple regression and conjoint analysis. Recent work has extended determinant attribute analysis beyond identification, by incorporating cost-benefit analyses of the efforts to improve these key features and the incremental effects on customer attraction and loyalty (Rust, Zahorik and Keiningham, 1995; Rust, Moorman, and Dickson, 2002).

A key question is whether or not the same models can be used to predict preference and return probabilities for different market segments. Current literature generally imposes an implicit factor structure that is the same for all customers, so that a single preference function may be imposed. For this to work well, the underlying dimensions of preference should be similar across segments, even if the individual attribute weights may vary. Managerial decisions oriented towards optimizing service quality in these papers (Rust et al., and others) are based on the notion that similar preference structures exist for key segments of service customers.

Prior literature generally holds that dimensionality may be similar, even if attribute importance (e.g., weights) and perceptual maps may vary (Stefflre, 1968, 1977). The question arises whether it is valid to assume that

Readers with comments or questions are encouraged to contact the authors via email. 
the attributes by which services may be evaluated have similar structure for different market segments. The present paper provides empirical evidence for a large and important industry (hospitality services) and suggests that diverse traveler segments, even if somewhat different in the importance of specific features in determining their likelihood of staying again, may be similar in the dimensionality by which they evaluate hotel-staying experiences.

\section{Factors of Preference Structure: Hospitality Industry}

An exploratory study was conducted using data gathered from the hospitality industry. Generalizing from a single database, no matter how extensive, should be guarded, but it was believed that the method of comparing factor structures might be effectively demonstrated, and similarity or differences in the factors of preference structures for different market segments might be useful in testing the above hypothesis that services may be evaluated with a common factor structure.

Data were obtained from privately held United States corporation that operates thirty-three hotel and motel properties in sixteen states (the $36^{\text {th }}$ largest privately-held hotel company in the U.S.). A variety of franchise labels are represented, including Best Western, Comfort Inn, Hampton Inns \& Suites, Holiday Inn, Holiday Inn Express, Howard Johnson, Rodeway, and independent labels. The 2002 survey data were obtained from 18,545 completed customer comment cards distributed in rooms, and other hotel locations. Properties were rated along twenty-three specific attributes of service quality, plus an overall rating, on a scale from below expectations (1), as expected (2), to better than expected (3). In addition, respondents were asked to indicate the likelihood they would stay at this property if they were to return to this area again, on a scale from $0 \%$ to $100 \%$. Similar data is reported in Rust, et al. (1995) and is standard in the hospitality industry. The usual non-response biases for self-selected survey respondents apply, but the present sample contains a range of responses (about $80 \%$ positive) for the set of attributes and overall assessments.

In an optional set of questions, respondents also indicated whether their trip purpose was for business $(30.9 \%)$ or pleasure $(69.1 \%)$, and whether they were male $(50.9 \%)$ or female $(49.1 \%)$. Percentages are shown for those who provided answers, and the following analyses examine and compare the preference structures revealed by segments based on trip purpose and, separately, for gender. We note that males were more likely to travel on business (39.9\% vs. $25.1 \%$ of females), although there were substantial numbers of both genders that traveled for each of type of trip (business or pleasure).

Table 1 presents the results of a Principal Component Factor analysis (PCA with Varimax rotation of factors with Eigenvalues of one or more) of the satisfaction ratings of the 5,484 respondents who indicated their primary trip purpose was for business. The primary loading structure is shown by ranking variables on the first factor in the order of their loadings on that factor (down to about .40, or the highest loading per factor, whichever is greater), then listing the remaining variables by their ranked loadings on the second factor (down to their highest loading on a factor, or about .40), then those highly loaded on the third factor, then those highly loaded on the fourth. This enables a quick visual comparison and interpretation of the primary loading structures, with variables assigned to each factor highlighted in bold.

This table reveals four factors that collectively represent $64.14 \%$ of the variance in the twenty-three hotel attributes. Factor 1 depicts "room quality," and correlates highly with perceptions of eleven attributes: carpet, room cleanliness, hot water, heat and air conditioning, bed, room appearance, bathroom, TV, everything working, quietness, and the value received for the price. Factor 2 represents five attributes of "staff quality": friendliness, check in and check out, efficiency, and services (wakeup, etc.). Factor 3 depicts "public facilities" (four attributes) such as meeting rooms, pool and recreation areas, lobby, and the building exterior. Factor 4 represents "restaurant quality," mainly a complimentary continental breakfast in these hotels, with three highly loaded attributes: food quality, breakfast appearance, and service quality. 
These factors are all intuitively reasonable and are similar to others that have been reported in the hospitality industry. What is important here is whether a similar structure is obtained for pleasure and other travelers.

Table 1: Rotated Component Matrix: Business Travelers

\begin{tabular}{|c|c|c|c|c|}
\hline \multirow[t]{2}{*}{ Hotel Attribute } & \multicolumn{4}{|c|}{ Component } \\
\hline & 1 & 2 & 3 & 4 \\
\hline Carpet & 0.722 & 0.153 & 0.231 & 0.117 \\
\hline Cleanliness & 0.712 & 0.230 & 0.191 & 0.156 \\
\hline Hot Water & 0.694 & 0.176 & 0.194 & 0.128 \\
\hline Heat \& A/C & 0.688 & 0.166 & 0.218 & 0.119 \\
\hline Bed & 0.677 & 0.190 & 0.194 & 0.142 \\
\hline Room Appearance & 0.672 & 0.200 & 0.309 & 0.156 \\
\hline Bathroom & 0.671 & 0.189 & 0.180 & 0.203 \\
\hline Television & 0.670 & 0.157 & 0.215 & 0.105 \\
\hline Everything Work & 0.654 & 0.246 & 0.150 & 0.204 \\
\hline Quietness & $\mathbf{0 . 5 0 3}$ & 0.206 & 0.156 & 0.190 \\
\hline Price/Value & 0.432 & 0.227 & 0.290 & 0.156 \\
\hline Friendliness & 0.196 & 0.838 & 0.122 & 0.132 \\
\hline Check In & 0.210 & 0.833 & 0.144 & 0.099 \\
\hline Efficiency & 0.269 & 0.811 & 0.151 & 0.169 \\
\hline Check Out & 0.268 & 0.783 & 0.205 & 0.148 \\
\hline Services (Wakeup, etc) & 0.318 & 0.637 & 0.198 & 0.246 \\
\hline Meeting Rooms & 0.403 & 0.203 & 0.740 & 0.179 \\
\hline Pool \& Recreation Area & 0.232 & 0.152 & 0.724 & 0.168 \\
\hline Lobby & 0.314 & 0.218 & 0.717 & 0.168 \\
\hline Building Exterior & 0.358 & 0.161 & 0.712 & 0.136 \\
\hline Food Quality & 0.212 & 0.152 & 0.164 & 0.839 \\
\hline Breakfast Appearance & 0.275 & 0.203 & 0.204 & 0.825 \\
\hline Breakfast Service Quality & 0.253 & 0.237 & 0.180 & 0.824 \\
\hline Eigenvalues & 5.616 & 3.757 & 2.850 & 2.576 \\
\hline Percentage of Variance Extrac & & & & \\
\hline Extraction Method: Principal C & alysis & & & \\
\hline Rotation Method: Varimax wi & lizatic & & & \\
\hline
\end{tabular}

Table 2 presents the results of the same Principal Components Factor Analysis (with Varimax rotation) of the satisfaction ratings of the 12,285 respondents who indicated their primary trip purpose was for pleasure. The primary loading structures are almost identical, with the same eleven, five, four, and three attributes defining the same four factors (64.14\% of total variance), respectively, "room quality," "staff quality," "public facilities," and "restaurant quality," respectively. The order of highly loaded attributes is almost identical.

A more precise measure of the similarity or agreement between factors obtained in different solutions is provided by Percy (1976), using a standard measure, the coefficient of congruence discussed by Harman (1967) and Cattell (1966). 


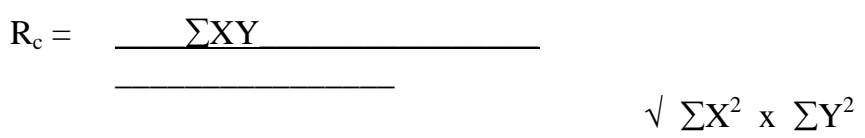

where $\mathrm{X}$ and $\mathrm{Y}$ are loadings of the same variable on the equivalent factor in solution $\mathrm{X}$ (in this case, business travelers) and Y (e.g., pleasure travelers), not deviations of loadings. Unlike the product-moment correlation coefficient, here one is summing over common variables, not individuals. ${ }^{1}$

For the comparison of factor structure for business travelers with pleasure travelers, the coefficients of congruence, $\mathrm{R}_{\mathrm{c}}$, for matching factors 1 through 4 are, respectively: .999056, .994395, 981269, and .995232, representing almost identical structure.

Table 2: Rotated Component Matrix: Pleasure Travelers

\begin{tabular}{|l|c|c|c|c|}
\hline \multirow{2}{*}{ Hotel Attribute } & \multicolumn{4}{|c|}{ Component } \\
\cline { 2 - 5 } & $\mathbf{1}$ & $\mathbf{2}$ & $\mathbf{3}$ & $\mathbf{4}$ \\
\hline Cleanliness & $\mathbf{0 . 7 1 8}$ & 0.208 & 0.215 & 0.147 \\
Carpet & $\mathbf{0 . 7 0 5}$ & 0.143 & 0.266 & 0.104 \\
Bed & $\mathbf{0 . 6 8 6}$ & 0.204 & 0.167 & 0.149 \\
Heat \& A/C & $\mathbf{0 . 6 8 3}$ & 0.146 & 0.228 & 0.110 \\
Appearance & $\mathbf{0 . 6 7 8}$ & 0.216 & 0.317 & 0.141 \\
Bathroom & $\mathbf{0 . 6 7 1}$ & 0.211 & 0.183 & 0.175 \\
Hot Water & $\mathbf{0 . 6 6 8}$ & 0.200 & 0.186 & 0.148 \\
Everything Work & $\mathbf{0 . 6 6 0}$ & 0.255 & 0.150 & 0.172 \\
Television & $\mathbf{0 . 6 4 0}$ & 0.150 & 0.250 & 0.120 \\
Quietness & $\mathbf{0 . 5 0 5}$ & 0.202 & 0.119 & 0.161 \\
Price/Value & $\mathbf{0 . 4 7 6}$ & 0.238 & 0.183 & 0.157 \\
Check In & 0.217 & $\mathbf{0 . 8 2 5}$ & 0.175 & 0.116 \\
Friendliness & 0.215 & $\mathbf{0 . 8 2 5}$ & 0.141 & 0.157 \\
Efficiency & 0.285 & $\mathbf{0 . 7 9 6}$ & 0.161 & 0.187 \\
Check Out & 0.291 & $\mathbf{0 . 7 8 3}$ & 0.199 & 0.168 \\
Services & 0.376 & $\mathbf{0 . 6 0 5}$ & 0.214 & 0.236 \\
Building Exterior & 0.343 & 0.191 & $\mathbf{0 . 7 5 3}$ & 0.086 \\
Lobby & 0.307 & 0.213 & $\mathbf{0 . 7 4 4}$ & 0.148 \\
Meeting Rooms & 0.422 & 0.223 & $\mathbf{0 . 7 2 4}$ & 0.210 \\
Pool \& Recreation Area & 0.262 & 0.168 & $\mathbf{0 . 6 1 1}$ & 0.212 \\
Food Quality & 0.196 & 0.158 & 0.147 & $\mathbf{0 . 8 4 2}$ \\
Service Quality & 0.238 & 0.248 & 0.154 & $\mathbf{0 . 8 2 4}$ \\
Appearance Breakfast & 0.264 & 0.211 & 0.209 & $\mathbf{0 . 8 2 1}$ \\
\hline Eigenvalues & 3.708 & 2.768 & 2.573 \\
Percentage of Variance Extracted = 63.94\% & & & \\
Extraction Method: Principal Component & & & \\
Rotation Method: Varimax with Kaiser Normalization & & & \\
\hline
\end{tabular}

\footnotetext{
${ }^{1}$ Percy computed $\mathrm{R}_{\mathrm{c}}$ for only the highly loaded variables that "define" the factors; to be more conservative and less arbitrary, we compute $\mathrm{R}_{\mathrm{c}}$ for all variables and loadings on each factor.
} 
Table 3 presents the results of the PCA factor analysis method for the satisfaction ratings of the 7,517 male respondents. The primary loading structures are almost identical, with the same eleven, five, four, and three attributes defining the same four factors (64.695\% of total variance), respectively, "room quality," "staff quality," "public facilities," and "restaurant quality," respectively. The order of highly loaded attributes is similar to that of Tables 1 and 2.

Table 3: Rotated Component Matrix: Male Travelers

\begin{tabular}{|l|c|c|c|c|}
\hline \multirow{2}{*}{ Hotel Attribute } & \multicolumn{4}{|c|}{ Component } \\
\cline { 2 - 5 } & $\mathbf{1}$ & $\mathbf{2}$ & $\mathbf{3}$ & $\mathbf{4}$ \\
\hline Carpet & $\mathbf{0 . 7 1 5}$ & 0.150 & 0.264 & 0.104 \\
Heat \& A/C & $\mathbf{0 . 7 1 4}$ & 0.168 & 0.189 & 0.139 \\
Hot Water & $\mathbf{0 . 6 9 9}$ & 0.175 & 0.164 & 0.184 \\
Cleanliness & $\mathbf{0 . 6 9 7}$ & 0.249 & 0.243 & 0.116 \\
Bed & $\mathbf{0 . 6 8 6}$ & 0.197 & 0.176 & 0.153 \\
Television & $\mathbf{0 . 6 6 3}$ & 0.152 & 0.225 & 0.131 \\
Bathroom & $\mathbf{0 . 6 5 4}$ & 0.198 & 0.224 & 0.194 \\
Everything Work & $\mathbf{0 . 6 5 1}$ & 0.244 & 0.165 & 0.201 \\
Appearance & $\mathbf{0 . 6 3 4}$ & 0.240 & 0.371 & 0.135 \\
Quietness & $\mathbf{0 . 5 1 0}$ & 0.221 & 0.173 & 0.178 \\
Price/Value & $\mathbf{0 . 4 3 5}$ & 0.270 & 0.269 & 0.127 \\
Friendliness & 0.207 & $\mathbf{0 . 8 4 0}$ & 0.142 & 0.155 \\
Check In & 0.221 & $\mathbf{0 . 8 2 9}$ & 0.157 & 0.125 \\
Efficiency & 0.291 & $\mathbf{0 . 7 8 6}$ & 0.175 & 0.204 \\
Check Out & 0.271 & $\mathbf{0 . 7 8 4}$ & 0.208 & 0.189 \\
Services & 0.357 & $\mathbf{0 . 5 8 6}$ & 0.228 & 0.280 \\
Building Exterior & 0.361 & 0.170 & $\mathbf{0 . 7 3 4}$ & 0.115 \\
Lobby & 0.322 & 0.223 & $\mathbf{0 . 7 2 4}$ & 0.148 \\
Meeting Rooms & 0.419 & 0.212 & $\mathbf{0 . 7 1 7}$ & 0.234 \\
Pool \& Recreation Area & 0.245 & 0.179 & $\mathbf{0 . 6 6 5}$ & 0.199 \\
Food Quality & 0.202 & 0.176 & 0.173 & $\mathbf{0 . 8 3 2}$ \\
Service Quality & 0.250 & 0.262 & 0.160 & $\mathbf{0 . 8 1 9}$ \\
Appearance Breakfast & 0.267 & 0.231 & 0.216 & $\mathbf{0 . 8 1 0}$ \\
\hline Eigenvalues & 3.766 & 2.882 & 2.605 \\
Percentage of Variance Extracted =64.695\% & & & \\
Extraction Method: Principal Component & & & \\
Rotation Method: Varimax with Kaiser Normalization & & & \\
\hline
\end{tabular}

Table 4 presents the results of the PCA factor analysis method for the satisfaction ratings of the 7,271 female respondents. The primary loading structures are almost identical, with the same eleven, five, four, and three attributes defining the same four factors $(64.476 \%$ of total variance), respectively, "room quality," "staff quality," "public facilities," and "restaurant quality," respectively. Once again, the order of highly loaded attributes is very similar to Table 3 (males), as well as Tables 1 and 2 (above). Comparing factor structures for male and female guests, the coefficients of congruence, $\mathrm{R}_{\mathrm{c}}$ are $.998484, .998185, .994288$, and .996243 , again indicating almost identical loadings for these segments. 
The evaluation factor structures thus appear to be extremely similar, for business compared to pleasure travelers, and for females compared to males. Next we considered whether the relative importance of these factors in determining decisions to stay again was similar. To estimate the importance of each evaluative factor in decisions to stay again, we estimated multiple regression models, with the four factors from each segment's PCA as independent variables, and the stated likelihood of staying again in the rated property (if returning to the area) as the dependent variable. As might be expected, the patterns were again similar, with some logical shifts in the importance of factors to each segment (see Tables 5 and 6, below).

Table 4: Rotated Component Matrix: Female Travelers

\begin{tabular}{|c|c|c|c|c|}
\hline \multirow[t]{2}{*}{ Hotel Attribute } & \multicolumn{4}{|c|}{ Component } \\
\hline & 1 & 2 & 3 & 4 \\
\hline Cleanliness & 0.741 & 0.215 & 0.185 & 0.159 \\
\hline Carpet & 0.716 & 0.154 & 0.231 & 0.109 \\
\hline Appearance & 0.699 & 0.214 & 0.293 & 0.150 \\
\hline Bathroom & 0.695 & 0.200 & 0.167 & 0.186 \\
\hline Bed & 0.682 & 0.212 & 0.181 & 0.125 \\
\hline Everything Work & 0.676 & 0.247 & 0.139 & 0.172 \\
\hline Heat \& A/C & 0.662 & 0.145 & 0.266 & 0.121 \\
\hline Hot Water & 0.657 & 0.200 & 0.236 & 0.133 \\
\hline Television & 0.650 & 0.177 & 0.223 & 0.127 \\
\hline Quietness & 0.474 & 0.176 & 0.155 & 0.188 \\
\hline Price/Value & 0.473 & 0.239 & 0.197 & 0.171 \\
\hline Friendliness & 0.215 & 0.826 & 0.145 & 0.159 \\
\hline Check In & 0.204 & 0.823 & 0.163 & 0.119 \\
\hline Efficiency & 0.281 & 0.815 & 0.146 & 0.185 \\
\hline Check Out & 0.291 & 0.782 & 0.205 & 0.155 \\
\hline Services & 0.380 & 0.621 & 0.217 & 0.203 \\
\hline Meeting Rooms & 0.421 & 0.200 & 0.731 & 0.193 \\
\hline Building Exterior & 0.354 & 0.208 & 0.727 & 0.097 \\
\hline Lobby & 0.310 & 0.239 & 0.722 & 0.170 \\
\hline Pool \& Recreation Area & 0.253 & 0.142 & 0.666 & 0.181 \\
\hline Food Quality & 0.206 & 0.152 & 0.151 & 0.843 \\
\hline Appearance Breakfast & 0.276 & 0.210 & 0.195 & 0.828 \\
\hline Service Quality & 0.241 & 0.246 & 0.171 & 0.825 \\
\hline Eigenvalues & 5.731 & 3.751 & 2.770 & 2.578 \\
\hline
\end{tabular}

Table 5 presents the regression analysis results for business vs. pleasure travelers' factors of hotel quality ratings used to predict their stay again likelihoods. As indicated by the constant, the average business traveler was $81.476 \%$ likely to stay again at the rated property, and the pleasure traveler $82.337 \%$ likely to do so. The four principal components "explained" $31.5 \%$ of the variability in business return likelihoods, and $28.0 \%$ for pleasure travelers $(\mathrm{p}<.001$ for both). Additional explanatory power might be obtained using less common factors, and could 
also provide additional insight into the determinance of features with lower communality with these principal components. For the major factors, both segments show significant and positive effects of satisfaction with each component. Based on the standardized (beta) coefficients and the zero-order correlations with stay-again, business travelers' loyalty appears somewhat more dependent on staff and services (check in/out, wakeup) than does pleasure travelers', and somewhat less on public facilities (pool, recreation areas, lobby). This seems intuitively reasonable.

Table 6 provides similar results for regression equations using the derived factor structures (and factor scores) for male vs. female guests. The models' explanatory power was $31.6 \%$ for males and $26.3 \%$ for females (p $<$ .001 for both). Again, the determinance of staff and service quality appeared to be somewhat greater for males than females. The explanatory power of restaurant quality appeared

Table 5: Regression Coefficients for Business vs. Pleasure Hotel Quality Factors and Stay Again

\begin{tabular}{|c|c|c|c|c|c|c|c|}
\hline & & $\begin{array}{c}\text { Unstandardized } \\
\text { Coefficients }\end{array}$ & & $\begin{array}{c}\text { Standardized } \\
\text { Coefficients }\end{array}$ & $\mathrm{t}$ & Sig. & Correlations \\
\hline Trip Purpose & & $\mathrm{B}$ & Std. Error & Beta & & & Zero-order \\
\hline \multirow[t]{5}{*}{ Business } & (Constant) & 81.476 & .562 & & 145.02 & .000 & \\
\hline & Room Quality & 9.448 & .561 & .373 & 16.846 & .000 & .414 \\
\hline & Staff \& Services & 8.814 & .624 & .312 & 14.121 & .000 & .353 \\
\hline & Public Facilities & 3.356 & .579 & .128 & 5.798 & .000 & .163 \\
\hline & Restaurant & 4.017 & .594 & .150 & 6.767 & .000 & .197 \\
\hline \multirow[t]{5}{*}{ Pleasure } & (Constant) & 82.337 & .430 & & 191.55 & .000 & \\
\hline & Room Quality & 9.406 & .444 & .359 & 21.174 & .000 & .401 \\
\hline & Staff \& Services & 7.050 & .457 & .261 & 15.433 & .000 & .305 \\
\hline & Public Facilities & 3.456 & .454 & .129 & 7.614 & .000 & .195 \\
\hline & Restaurant & 4.408 & .455 & .163 & 9.688 & .000 & .196 \\
\hline
\end{tabular}

Dependent Variable: Stay Again. Significant R Squares: Business (31.5\%); Pleasure (28.0\%)

Table 6: Regression Coefficients for Males' vs. Females' Hotel Quality Factors and Stay Again

\begin{tabular}{|c|c|c|c|c|c|c|c|}
\hline & & $\begin{array}{l}\text { Unstandardized } \\
\text { Coefficients }\end{array}$ & & $\begin{array}{c}\text { Standardized } \\
\text { Coefficients }\end{array}$ & $\mathrm{t}$ & Sig. & Correlations \\
\hline GENDER & & $\mathrm{B}$ & Std. Error & Beta & & & Zero-order \\
\hline \multirow[t]{5}{*}{ Male } & (Constant) & 81.270 & .522 & & 155.76 & .000 & \\
\hline & Room Quality & 10.127 & .542 & .376 & 18.693 & .000 & .419 \\
\hline & Staff \& Services & 8.818 & .562 & .315 & 15.694 & .000 & .358 \\
\hline & Public Facilities & 4.171 & .550 & .152 & 7.583 & .000 & .211 \\
\hline & Restaurant & 2.737 & .551 & .100 & 4.969 & .000 & .154 \\
\hline \multirow[t]{5}{*}{ Female } & (Constant) & 82.439 & .557 & & 147.92 & .000 & \\
\hline & Room Quality & 9.094 & .570 & .345 & 15.961 & .000 & .379 \\
\hline & Staff \& Services & 7.678 & .603 & .275 & 12.725 & .000 & .308 \\
\hline & Public Facilities & 3.902 & .583 & .144 & 6.689 & .000 & .155 \\
\hline & Restaurant & 3.804 & .586 & .140 & 6.488 & .000 & .188 \\
\hline
\end{tabular}

Dependent Variable: Stay Again. Significant R Squares: Males (31.6\%); Pleasure (26.3\%)

somewhat larger for female guests than for males. Room quality was the most important factor for all four segments.

\section{Discussion and Conclusions}

It appears in this large database, that the preference structures involve similar dimensions, meaningful to all four segments. Weights on these dimensions may be somewhat different, as inferred by the differences in explanatory power of individual components and attributes, but the "grammar" of preference is similar, with slightly different emphasis on specific features sought by each segment. 
These results are encouraging and congenial to the hypothesis that customers may use similar components to evaluate choice objects, while differing in the importance of particular attributes in determining their specific preferences. Extensions should examine other services and products, and test to see if dimensionality is similar for different market segments evaluating them. In addition to the coefficients of congruence, which were used here to examine the similarity of primary loading structures of the major structural factors, it may also be productive to evaluate structural similarity using confirmatory factor analysis, which may provide additional evidence and comparative validity.

\section{References}

1. Cattell, Raymond B.(1966), "The Meaning and Strategic Use of Factor Analysis" in Raymond B. Cattell, ed., Handbook of Multivariate Experimental Psychology. Chicago, Rand McNally \& Company.

2. Harman, Harry (1967), Modern Factor Analysis (second edition), Chicago: The University of Chicago Press.

3. Myers, James H. and Mark I. Alpert (1968), "Determinant Buying Attitudes: Meaning and Measurement," Journal of Marketing, 32 (October), 13-20.

4. Myers, James H. and Mark I. Alpert (1997), "Determinant Buying Attitudes: Meaning and Measurement," republished in Marketing Management_(Marketing "Classics" Series), 6 (Summer), pp. 50-56.

5. $\quad$ Percy, Larry (1976), "An Argument In Support of Ordinary Factor Analysis of Dichotomous Variables," Advances In Consumer Research, 3, pp. 143-149.

6. Rust, Roland T., Anthony J. Zahorik, and Timothy L. Keiningham (1995), "Return on Quality (ROQ): Making Service Quality Financially Accountable," Journal of Marketing, 59 (April), 58-70.

7. Rust, Roland T., Christine Moorman, and Peter R. Dickson (2002), "Getting Return on Quality: Revenue Expansion, Cost Reduction, or Both," Journal of Marketing, 66 (October), 7-24.

8. $\quad$ Stefflre, Volney (1968),"Market Structure Studies: New Products for Old Markets and New Markets (Foreign) for Old Products," in Bass, King, and Pessemier, Applications of the Sciences in Marketing Management. New York: John Wiley. Chapter 10, pp. 251-268.

9. Stefflre, Volney (1977), "New Products: Organizational and Technical Problems and Opportunities," in Alan D. Shocker (ed.) Analytic Approaches to Product and Marketing Planning, (Cambridge, Mass.: Marketing Science Institute, 1979), 415-480. 